\title{
Studies in Mathematics Education: Curriculum Analysis from Indigenous Knowledge and Gender Perspective
}

\author{
Abatar Subedi \\ abatar.subedi@tucded.edu.np \\ Lecturer \\ Central Department of Education, T.U., Kirtipur
}

\begin{abstract}
This paper aims to analyze the curriculum of the course 'Studies in Mathematics Education (Math Ed. 539)' from indigenous and gender perspectives. For, the curriculum of that course, particularly objectives, contents, textbooks, teaching/learning methods and evaluation are visualized and analyzed. The experiences and insights of two teachers of that course were included and analyzed concerning to IK and gender perspectives, by taking in-depth interviews with the help of semi-structured interview guidelines. The result shows that there are sufficient space and provision of incorporate IK in the curriculum and teachers are trying to implement this course as much as possible from the cultural perspective of mathematics education. The curriculum displays gender friendly and neutral aspects in terms of gender and teachers are using gender friendly methodology while implementing the course. However, the evaluation system is not more flexible as expected by female teacher. Thus, the inclusion of IK with particular local knowledge and making gender friendly curriculum is necessary for the courses of teacher preparation in mathematics education.
\end{abstract}

Keywords: Indigenous knowledge, gender issues, curriculum, mathematics education

\section{Introduction}

Addressing the issues of indigenous knowledge (IK) and gender in the curriculum of teacher preparation courses in University education, particularly at the master level is an ongoing phenomenon for the educational researchers. There are several such courses under the faculty of education of Tribhuvan University (TU) of Nepal including the courses of mathematics education. The students (or prospective mathematics teachers) who will complete the master degree in mathematics education are expected to have several pedagogical and technological skills in addition to the content knowledge required for the mathematics teacher at secondary level in school education. For the fulfillment of such expectations, to what extent the curriculum of mathematics education, particularly in the curriculum of 'studies in mathematics education (Math Ed. 539)'emphasizes and demonstrates the pedagogical skills which are required for the prospective mathematics teachers to develop the skills of integrating IK and promoting gender friendly pedagogy are needed to investigate. 
Several literatures have defined indigenous knowledge differently. However, IK is a local knowledge that is unique to a given cultural acquired by local people through the accumulation of experiences, informal experiments, and intimate understanding of the environment in a given culture (Abah et al., 2015 \& Chikaire et al., 2012). According to Langill (1999), IK is considered to be cultural knowledge in its broadest sense, including all of the social, political, economic and spiritual aspects of a local way of life (p.4). The importance of bridging such IK in day to day teaching and learning mathematics are highlighted in several researches including Kaino (2013); Chahine (2013); Moloi (2013); Chigeza and white house (2014); Kaino and Kasanda (2015); Jojo (2015); Subedi (2018) and so on. Thus, it is expected that the curriculum of mathematics education at master degree and other professional courses of teachers' preparation should give emphasis in building capacity of prospective mathematics teacher in integrating IK for meaningful teaching and learning mathematics.

Similarly, adopting gender sensitive pedagogy in addition to use of IK in teaching and learning mathematics from school to University education is an essential aspect of mathematics education. There is gender gap in mathematics performance, particularly girls have low performance in mathematics at school level in the context of male dominated society like in Nepal as described by the paper of Panthi and Belbase (2017). Likewise, the report of NASA (2013) as published by Ministry of Education (MoE, 2015) shows that there was significant difference between boys and girls in mathematics achievement where boys outperformed in all the content areas of mathematics at grade eight (p. 58). Such gender gaps in mathematics performance are existed due to several factors including discriminatory attitudes, beliefs and attitudes not only within families and communities for girls, but within the school environment (Jones, 2016; p.1). The research paper of Jones (2016) also summarized the factors that have central role in contributing low participation and performance of girls in mathematics in Tanzania as:

stereotypes of mathematicians and mathematics related professions as 'masculine', belief that girls and women are not as capable in the science, mathematics and technology areas, unfavorable classroom environments and interactions, pedagogy, curriculum and resources, assessment practices, lack of informed career guidance encouraging girls to pursue studies in the area of mathematics, lack of confidence and motivation to excel in and pursue mathematics (p.1).

Hall (2012) stated that these deeply entrenched societal views and stereotypes will be difficult to change and will take many years to slowly evolve; however, change can begin now from within the mathematics classroom (p.70). Likewise, Gallagher and Kaufman (2015) explained that the common perception such as 'gender stereotype that girls do not like mathematics and are not as good at it as boys' existed in the society always discourage girls from engaging in mathematics study which limits opportunities for women in mathematics and related fields (p.316). Ajai and Imoko (2015) suggested that the contributing factors to generate gender gap in mathematics achievement are due to classroom interactions; students' attitudes, interest and self-esteem; teachers' gendered attitudes, curricular materials; beliefs, social and cultural norms (p.48).

These literatures suggest that teacher is a major responsible person who can reduce gender gap in mathematics performance by applying varieties of teaching and learning strategies which demonstrate gender friendly learning environment to uplift girls' participation, interaction, 
motivation, and achievements in mathematics. It is also expected that the classroom pedagogical activities may also influence the societal and other stereotypes behaviors that are existed in this contemporary society, particularly male dominated society like in Nepal.

That is why preparing mathematics teachers who can address these issues of IK and gender in teaching and learning mathematics depends upon the knowledge they can learn from the curriculum of mathematics education. In such context, it is expected that the curriculum of mathematics courses which are implemented for the prospective mathematics teachers need to have sufficient inclusion of pedagogical content knowledge about how and why should integrate IK and why should to use gender sensitive pedagogy to make mathematics learning meaningfully and culturally relevant.

\section{Objectives}

The objective of this paper was to analyze curriculum of mathematics education at master level, particularly the curriculum of the course 'Studies in Mathematics Education (Math Ed. 539)' from the perspective of indigenous knowledge and gender. The analysis was done only from the aspects of syllabus coverage; objectives of the curriculum, contents, teaching/learning methods adopted to implement this curriculum, and assessment practices in it where IK and gender perspective were viewed as central in each aspect.

\section{Literature Review}

There are several literature addressing the importance of incorporation of indigenous knowledge in mathematics curriculum of teachers professional and academic development courses and making mathematics curriculum gender friendly including the literature discussed in the following paragraphs.

Including culturally responsive teaching in the curriculum of teacher preparation courses like mathematics education is some important aspects for promoting IK and reducing gender gap in mathematics performance. Tutak et al. (2011) stated that culturally responsive teaching is to address cultural diversity like gender, ethnicity, experiences and capabilities of students while teaching mathematics in the classrooms. Culturally responsive education makes mathematics more meaningful by aligning instruction with the cultural paradigm and lived experiences of students (Beatty, 2016). These cultural and lived experiences when connected with classroom teaching can encourage to integrate indigenous knowledge or local knowledge with mathematics teaching.

IK is a local knowledge that is unique to a given cultural acquired by local people through the accumulation of experiences, informal experiments, and intimate understanding of the environment in a given culture (Chikaire et al., 2012 \& Abah et al., 2015); IK evolves in the local environment, specifically adapted to the requirements of local people and condition (Langill, 1999, p.3). IK is also named as folk knowledge, people's knowledge, traditional wisdom or traditional science, and is passed from generation to generation, usually by word of mouth and cultural rituals, and has been the basis for agriculture, food preparation and conservation, health care, education, and the wide range of other activities that sustain a society and its environment 
in many parts of the world for many centuries (Senanayake, 2006, p.87). Moreover, Battiste (2002) stated that distinctive features of IK and pedagogy are learning by observation and doing, learning through authentic experiences and individualized instruction, and learning through enjoyment (p.18). These understandings of IK highlighted that its importance with the connection of classroom mathematics is invaluable.

The research of Kaino (2013) showed that the illustration of cultural artifacts to learn mathematical concepts in classroom makes mathematics more meaningful, clear for understanding and reduce the unnecessary remembrance of rules to obtain solution. This study also explained that through the illustration processes, learners can learn and develop mathematical interest through reflecting and appreciating on what exists in their tradition. Regarding to curriculum of mathematics Kaino (2013) has recommended that the inclusion of IK is necessary because it make clear understanding of mathematical concepts and for long-term retention of knowledge. Chahine (2013) capitalized the role of IK system for cognitive development with its vital contribution for successful and meaningful mathematics learning in any context. He further explained that the mathematical structure can be found in IK like in indigenous music, architecture, mural decorations, indigenous games, bead work, weaving, cultural artifacts, and other social system and activities.

The use of cultural artifact in teaching school geometry is supportive for better understanding such geometric concepts (Jojo, 2015). The integration of indigenous game like Morabaraba game in teaching encourage students to understand mathematics. Similarly, the research of Subedi (2018) showed that the inclusion of IK and its practices which are relevant to mathematical concepts such as cultural measurement system; artifacts; and other cultural objects with the day to day teaching learning mathematics make learning meaningful, effective and permanent, reduces abstractness, promote culturally responsive pedagogy, and enhance ethno-mathematics. It is also recommended that the curriculum of teacher preparation courses, particularly in mathematics education should include such IK system which help them to bridge IK with future mathematics teaching.

Tsindoli et al. (2018) explained that any types of mathematics, including western mathematics, is greatly influenced by ideas and activities that are important in specific cultures and therefore, should be respected and not taken as primitive (p.77). Tsindoli et al. (2018) also recommended that exploration of indigenous mathematical knowledge should be part of the curriculum design process and indigenous mathematical knowledge should be integrated into school mathematics curricula for clear understanding of concepts and for long-term retention of mathematical knowledge (p.86). The study of Kaino and Kasanda (2015) argued that the use of indigenous materials, approaches, and technology for competency in teaching learning mathematics would be regarded as an effective way of communication for easy grasping of mathematical knowledge (p.73).

Similarly, addressing gender issue in the curriculum of teacher preparation courses, particularly in the curriculum of mathematics education is the concerning aspect of this research paper. This aspect in curriculum views the issues of gender equality and equity, gender gaps and other 
stereotypes which influence the overall performance of girls and women in mathematics. For Cela (2016) highlighted that gender stereotypes are highly detrimental to academic and personal achievement of boys and girls alike, both in the short and long term and stereotypes retain inequality and do not allow individual growth and discovery, particularly for girls (p.553).

Historically, males were thought to be more suited than females to studying mathematics and being engaged in related areas (Leder, 2019, p.289). Leader (2019) further claimed that assumptions that gender differences in mathematics learning were, at least in part, the result of social structures, inadequate educational opportunities, and biased instructional methods and materials shaped much of the work undertaken (p.292). Such gender stereotypes have affected in choice of subjects for female in learning and in participation of classroom activities in mathematics. when gender stereotypes are eliminated, most inequalities towards girls and women are avoided and odds for equal chances within school and life domains are increased (Cela, 2016, p.553).

Likewise, Gallagher and Kaufman (2005) explained that the common perception such as 'gender stereotype that girls do not like mathematics and are not as good at it as boys' existed in the society always discourage girls from engaging in mathematics study which limits opportunities for women in mathematics and related fields (p.316). Yacoubi (2015) pointed that even in the developed countries, where equity in education was reached a long time ago, the rates of enrollment of girls in mathematics courses are relatively low (p.147).

Ajai and Imoko (2015) have stated that there are several factors which contribute to generate gender gap in mathematics achievement including the issues such as classroom interactions, students' attitudes, students' interest and self-esteem, teachers' gendered attitudes, curricular materials, beliefs, social and cultural norms (p.48). Similarly, the study of Yacoubi (2015) has listed some factors such as: negative socio-cultural attitudes, household task at home, gender biased curriculum, poor didactic materials, lack of school facilities, lack of sponsorship, unmotivated and unqualified mathematics teachers, lack of moral and financial parental support, lack of self confidence among the girls, poor performance in exams, and so on are responsible in generating gender problem in mathematics education (p.147).

However, the study of Ajai and Imoko (2015) showed that students' achievement and retention in algebra are not dependent on gender, but function of method, and suggested that there is a need to give boys and girls exactly the same opportunities and challenges in the mathematics class (p.49). The research of Hall (2012) showed that gender issues still exist in mathematics even in developed countries, including Canada where gender gap is particularly wide in terms of students' attitudes and participation: male have substantially more positive attitudes towards mathematics and higher levels of participation in non-mandatory levels of mathematics than do females (p.59). Jones (2016) revealed that girls and boys attend the same classes and be exposed to the same lessons by the same teachers, but the ways in which those lessons are experienced can be very different (p.3). Jones (2016) research in Tanzania also found that boys were assigned more leadership role, asked to demonstrate processes at the front of mathematics class, and learning resources were more supportive and relevant for them. Thus, such discriminations in 
curriculum implementation process in the classroom and other stereotypes like mathematics is the domain of boys and men, found in society generates obstacles to select mathematics in general and participation in mathematics-related careers for girls and women.

In context of Nepal, the paper of Panthi and Belbase (2017) explained that gender issue is belongs to the social issues for teaching and learning mathematics. According to them female students may have less interest in studying mathematics beyond schools. These situations are due to less priority of parents given to daughters, early marriage for daughters, having extra burden to take care at home, and due to other social taboo such as girls cannot learn mathematics which generate challenges for the teachers to provide equal opportunities in mathematics classroom (Panthi \& Belbase, 2017, pp. 6 -7). Because of such social stereotypes, female students have poor participation and performance in mathematics classroom. According to report of Ministry of Education (MoE), the result of NASA (2013) explored that there is significant difference between boys and girls in mathematics achievement where boys outperformed in all content areas of mathematics at grade eight of school education (MoE, 2015, p.58).

Hence, the literature as reviewed above show that at least the curriculum of the teacher preparation courses like mathematics education at master level need to rethink their courses from IK and gender perspectives. If the mathematics teachers have capability of integrating IK and promoting gender friendly pedagogy in day to day classroom teaching and learning then they can make mathematics learning meaningful, relate learning with culture, and provide equal opportunities for both boys and girls in classroom activities. In such context, this study tried to visualize curriculum of mathematics education, particularly the curriculum of 'Studies in Mathematics Education (Math Ed. 539)' from the perspective of IK and gender in general.

\section{Methodology}

This study was intended to analyze curriculum of mathematics education at master level of Tribhuvan University of Nepal, particularly the curriculum of the course 'Studies in Mathematics Education (Math Ed. 539) from indigenous knowledge (IK) and gender perspectives. The curriculum was critically approached and evaluated by using desk research methodology. The objectives, contents, teaching/learning methods, learning resources and overall evaluation process of newly revised curriculum, particularly the syllabus of that curriculum were the major aspects of analysis in this research. The inclusion of IK and priorities of addressing gender issues on that aspects of curriculum were visualized. For the empirical information, two mathematics teachers (one male and one female) who are teaching and involving to prepare this course were interviewed by using semi-structured interview schedule. Their insights and experiences towards the issues of addressing IK and gender in the teacher preparation courses like the course of Math Ed. 539 of mathematics education were recorded and then transcribed. The transcripts were analyzed by using logical methods as described for general inductive approach described by Thomas (2006). The researcher followed the codes and policies for research ethics as much as possible such as honesty, objectivity, integrity, carefulness, openness, responsible publication, respect for colleagues, legality, confidentiality and respect to intellectual property. 


\section{Results and Discussion}

This section includes the results of analysis of the curriculum of the course Math Ed. 539 in mathematics education and discussed the results with the literature related to indigenous knowledge and gender issues in mathematics education. This section is also divided into three subsections with separate headings related to major aspects of curriculum, inclusion of IK and addressing gender issues in the curriculum of that course.

\section{Major Aspects of the Curriculum in the Course of 'Studies in Mathematics Education'}

Mathematics education is a specialization courses studying under the Faculty of Education (FoE) of the Tribhuvan University (TU), Nepal. To prepare mathematics teachers for all levels of school education is one of the objectives of this course in University. Likewise, students (prospective teachers) who will complete the master degree in mathematics education from TU are expected to have rich pedagogical skills in addition to content knowledge required for the teacher of mathematics at secondary level of school education. The courses of mathematics education at master level in education can be classified into four categories. The first category includes the core educational courses which will provides several theoretical knowledge for the prospective teachers in mathematics of school education including the concepts fundamental philosophies of education;sociological, behavioral, and other educational theories of learning; process and model of curriculum development, psychology of education; measurement and evaluation skills; techniques of educational research methodology; and other contemporary issues of education.

The second category includes the pure mathematical courses which will provide higher and abstract mathematical concepts through which prospective mathematics teachers can develop reasoning capacity and logical power for higher order thinking in mathematics education including problem solving and theorem proving skills of mathematics. The third category demonstrate more pedagogical courses which are expected to develop several pedagogical content knowledge of mathematics education including the concepts of behaviorist, cognitive, and constructivist learning theories; varied issues and research techniques of mathematics education. The courses in this category are also aimed to provide the knowledge of several teaching and learning methods; teaching and learning materials; current issues related to mathematics teaching, learning, and research; and other pedagogical aspects of mathematics education for the prospective mathematics teachers.

The final category provides the interdisciplinary courses like operation research, and information and communication technology (ICT) in mathematics education; and other practical courses like thesis writing and teaching practicum. It is required to choose only one interdisciplinary course and other two practical courses are compulsory for the prospective teachers of mathematics education. Thus, it is expected that all courses in these four categories are equally valuable to become a qualified mathematics teacher for school education.

Among the courses in third category as described above, Studies in Mathematics Education (Math Ed. 539) is one of the important and valuable course for the future teacher of mathematics education. This course is theoretical in nature which is implemented in the third semester at master degree in mathematics education having three credit hours within 48 teaching hours. 
This course aims at giving exposure to students about some of the books written in mathematics education that are used all over the world extensively. Equally, the course Math Ed. 539 is aimed to let students (prospective teachers) pick up global issue which is locally important, write an essay and give seminar related to components of mathematics education, like nature of mathematics, pedagogies for mathematics, teacher development, assessment strategies and research agenda.

Hence, the course is flexible in terms of choosing issue for seminars where students can select the issue of IK and gender in their own interest. With these broad aims of the course, there are eight general objectives intended to achieve when students will complete it. The general objects are mainly focus to make students knowledgeable about the strength of worldly renounced books of mathematics education by appraising them; provide in-depth exposure on different curriculum and their materials in the world; make philosophically aware, and enable to present opinion on the issues regarding to mathematics education; make students capable in preparing contextual curriculum and in critically analyzing it; and develop capacity of analytic writing together with participation in the seminars of mathematics education.

The contents included in this course are covered into five broad categories which are nature of mathematics and mathematics education; curriculum studies; research in mathematics education; review and appraisal of selected books/chapters; and analytical write-up and organization of seminars. The general instructional techniques recommended in the curriculum of this course are to focus prospective mathematics teachers on intensive and extensive reading of the available books together with individual and group discussion; collaborative lectures; and assigning projects, seminars, and analytical writing on the issues of mathematics education.

There are several specific instructional techniques advocated in the curriculum of the course Math Ed.539 including to involve students on internet browsing to search materials for reading the contents and to make seminars. The focus on classroom discussion on several issues of mathematics educations including the issues of indigenous knowledge, gender, technological, popularization, and so forth is one of the in-depth discourse implemented in the classroom as expected by curriculum. The curriculum has also expected that the classroom instruction of this course should be focus on intensive and extensive reading to appraisal books, chapters of books, articles, curriculum of mathematics, and to write seminars, articles, and projects about the current issues in mathematics education.

The curriculum of the course Math Ed. 539 has provisioned to take internal and external evaluation for the students who are studying it. The internal evaluation covers 40 percent points which is done by subject teachers by taking first, second and third assignments together with evaluating students regularity and participation in the teaching/learning activities in the course intervention. The external evaluation is conducted by dean office of FoE which covers 60 percent points with the help of written achievement test. This test includes ten multiple choice questions each of one point, six short responses questions each of five point, and two extended response questions each of ten points. Finally, the sum of internal and external points will be the final achievement of the students. 
There are several recommended and reference books to cover the contents of the course including the books: a post-modern perspective on curriculum of Doll (1993), critical issue in mathematics education of Ernest et al. (2009), issues in mathematics education written by Gates (2001), what is mathematics really of Hersh (1997), 18 unconventional essays on nature of mathematics of Hersh (2006), studies in mathematics education of Acharya (2017), and new mathematics education and research of Maaz and Schloeglmann (2006). Most of these books are more valuable and worldly famous in mathematics education.

\section{Visualizing Curriculum from the Perspective of Indigenous Knowledge}

Curriculum is considering a guiding documents for the implementation of any course, in particular the course of Math Ed. 539. There are several aspects in the society which are required to include in the curriculum of teacher preparation course including the indigenous knowledge. IK is a local knowledge acquired by local people through the accumulation of experiences, informal experiments, and intimate understanding of the environments in a given culture (Abah et al., 2015 \& Chikaire et al., 2012). The inclusion of such knowledge in the curriculum, particularly in approaches of teaching is an important aspect to make mathematics cultural relevant and meaningful as supported by several literatures as described in literature review sections. For example, the inclusion of IK in the curriculum of mathematics is necessary because it make clear understanding of mathematics concepts and for long term retention (Kaino, 2013), its vital contribution for successful and meaningful mathematics learning (Chahine, 2013), cultural artifacts are better to learn geometric concepts (Jojo, 2015), and so on.

With listing such importance of IK in mathematics, I visualized the curriculum of the course Math Ed. 539 and thus analyzed it from IK perspective by including the experiences of participants together with my reflection on it. How and where indigenous knowledge are acknowledged, empowered and incorporated in the implementation of this course for the prospective mathematics teachers of school education was considered an important things to be analyzed. One participant expressed his views regarding the objectives of this course as: the course Math Ed. 539 was basically designed to strengthen prospective mathematics teachers' knowledge on nature of mathematics and mathematics education; current issues of mathematics education; to inform well-known research ideas in mathematics education; to make capable on how to review well-known books, articles; and to make awareness on different curriculum designs including local curriculum practices. Likewise, next participant explained as:when I became a teacher at university, I realized that this course is valuable for the teacher educator which has acknowledged prospective mathematics teachers in several dimensions including issues in mathematics education like ethno-mathematics and IK; develop communication, writing, sharing, and presentation skills for them; and help them to understand current society from latest context regarding how mathematics education going on and contributing for society.

These experiences of selected teachers indicate that the course was prepared to enhance several skills for the prospective mathematics teachers including to raise awareness of ethno-mathematics and different dimension of curriculum together with the concepts of local curriculum. Regarding to the contents of the course Math Ed. 539 from IK perspective the course teachers experienced as: there are sufficient space given in the curriculum of this course to incorporate and inclusion 
of indigenous knowledge such as cultural nature of mathematics in which ethno-mathematical concepts are discussed ... it raises culture creates mathematics, ... similarly in studying curriculum studies where curriculum is analyzed from different perspective, discussed cultural dimensions and multicultural perspectives. In the contents of research, we are focusing on cultural issues including IK, discussing on strong social turn in mathematics education research; and focusing ethnography and auto-ethnographic types of research.

The above responses and experiences of the participant and connection with the contents as described in the curriculum justify that the curriculum of this course give sufficient emphasis on integrating IK. Similarly, the participant reported as: there is a provision of writing long essay, reviewing books and conducting seminars... In conducting such activities different topics are assigned to students related to several issues including the issues of culture, IK, ethnomathematics, social practices, and cultural anthropology of mathematics.... such activities encourage and empower students to address their own cultural practices of mathematics such as mathematics practices in limbu, rai, newar and other culture of Nepalese context. This explanation revealed that the activities required to complete the course and implementation process of the curriculum of Math Ed. 539 acknowledge IK, empower to make local curriculum like for limbu community, and encourage cultural aspects of mathematics. As my experienced, there are much space to bridge IK while implementing teaching learning activities such as we can give assignments to students to explore their cultural ethno-mathematics, find indigenous artifacts, practices and other activities which are helpful to teach school mathematics effectively. These practices can make connection of higher mathematics learning with students' cultural practices which is regarded as an important skills required for the prospective school teachers.

Moreover, the participant reported as: I am using the book 'fatalism and education' written by local writer Dor Bahadur Bist to teach curriculum of indigenous people like rai community, and using the book of D'Ambrisio to teach ethno-mathematics, and equally emphasis these books to give assignments like long essay and seminars works. Such materials are seen to encourage IK in teaching such course. Furthermore, the participant realized that "using indigenous knowledge and practice in classroom teaching make mathematics learning more reflective, increase interest and develop positive attitude like mathematical concepts are also due to contribution of our culture". The other participant expressed her views as: I emphasis IK and bridged it to teach almost all contents of this course directly or indirectly like to discuss different perspectives of curriculum, researches in mathematics education, and so on. The inclusion of IK on this type of teacher preparation course is valuable because it connects local knowledge with global context, respect cultural mathematical practices, and... our government also giving priorities of local knowledge. These reflections of selected participants show that the teachers who are teaching the curriculum of Math Ed.539 have given priorities to incorporate IK in curriculum and classroom teaching is acknowledgeable.

Regarding to the recommendation and reference books to cover the courses of the curriculum Math Ed. 539, the participants have experienced as: these books have encouraged several issues of mathematics education including indigenous knowledge, practices as well as ethno-mathematics perspectives, cultural aspects of curriculum, and researches in mathematics education which emphasis the importance of IK in mathematics education like what is mathematics really of Hersh 
(1997), issues in mathematics education written by Gates (2001), and studies in mathematics education of Acharya (2017). These experiences show that the text books of the curriculum implementations are also empowered students to see the importance of incorporation of IK in the courses of teacher academic and professional development. These books can energize students to choose the issue of IK while learning mathematics education.

From the overall discussion of this subsection, it is concluded that there is sufficient inclusion of IK in the curriculum of the course Math Ed. 539 directly and indirectly. The provision of several activities like writing long essay, reviewing books and conducting seminars to students of master degree in mathematics education have provided the flexibility to choose research issues for them. According to selected teachers' experiences, these flexibility helps teachers and students to incorporate IK into their discussion, writings, and seminars as well as to focus on indigenous cultural and local knowledge, practices and materials which are valuable for mathematics education.

\section{Visualizing Curriculum from Gender Perspective}

Visualizing curriculum from the gender perspective is a concerning issues of this research. Gender is understood as the culturally relative term derived from the social science; it is a product not of biology but of social practice(Leach, 2003, p.16). The term gender here is used to describe all the socially driven aspects of our lives: the role we play, the responsibilities we take on, our expectation for the future, and the behaviors and activities we engaged in.There are several activities and behaviors in the society which continuously constructs gender issues. Hall (2012) showed that gender issues still exist in mathematics even in developed countries where male have substantially more positive attitudes towards mathematics and higher levels of participation in non-mandatory level of mathematics.

There can be seen that boys and girls in the same class of same teachers are experiencing differently (Jones, 2016). This implies that there may be several gender issues regarding to the curriculum of mathematics education. Leach (2016) stated that the key terms related to analyze gender issues are several including to observe gender stereotypes, gender relations, gender roles, involving in productive and reproductive work, and gender analysis involves examining relationships between women and men, and the inequalities and power differences between them, in systematic way (p.19).

From such context, I visualized the curriculum of Math Ed. 539 such that how it is considering gender equality, equity, gender sensitivity, gender neutrality, gender needs, empowerment, and other social issues including how participants understand the concepts of gender in mathematics education. According to female participant, "gender is the socially constructed behaviors, it raises the issues of equality and equity for the marginalized people in the society, particularly for girls and women students in mathematics education. Female students are generally belonging to the marginalized group while learning, enrolling and involving in the field of mathematics... there are several socially constructed stereotypes like girl do not like mathematics, they do not do better performance, girls are need to do more household work etc. but now these concepts are slowly decreased due to technological and other social awareness in developing countries like Nepal". 
The other participant opined as: I do not generally believe that girls have low participation, low enrollment, but they are equally capable with boys, can get highest marks than boys...however, low enrollment is seen in the evening classes. Girls may have low participation in higher mathematics education due to early marriage, engaging in household works in comparison to boys and so on. These views indicate that they understood gender disparity is created by social activities and behaviors which are also reflecting while learning mathematics. Their experiences also indicate that girls' enrollment in the master degree in mathematics education is minimum in comparison to boys due to societal activities and behaviors. But they are not cognitively and academically poor in comparison to boys in mathematics education.

Regarding to curriculum of Math Ed. 539, both participant agreed. They responded as: the curriculum of the course Math Ed 539 in mathematics education ensure equal opportunities to both boys and girls, the language and contents of the curriculum are not showing gender bias. We apply gender responsive pedagogy while teaching this course, textbooks recommendation for this course are free from gender bias. These experiences indicate that the curriculum of Math Ed. 539 is free from gender bias, provide equal opportunities to all students.

Regarding the issues of gender in the curriculum of Math Ed. 539, I asked participant such as how do you address such issue in classroom practices. They replied as: there is the provision of internal assignments, while conducting it, we give the task related to gender issues, gender role, gender bias, and so on for the discussion of curriculum dimension, in the preparation of seminars and in the writing of long essay, article etc. That means that there is not direct inclusion of gender issues in the curriculum of that course. However, teachers are trying to address such issues while implementing curriculum in several activities of learning in mathematics education of master degree. One participant also responded as: "I am always encouraging girls' students for the presentation of seminars together with boys and adopt student centered approaches of teaching, the language of textbooks and curriculum are neutral, and examples are presented from gender sensitive perspective”.

These activities of classroom instruction and overall curriculum show that the curriculum is gender friendly. When I studied the curriculum, particularly the syllabus of the course Math Ed. 539, I did not find any gender bias in it in terms of gender perspective. But it was found that the curriculum displayed equality on opportunities, neutrality on language, an encouraging students centered approaches for the implementation of it. The implementation of gender friendly teaching methodology by the teacher are encouraging students equally and the priority given for girls' students in some particular tasks empower girls to learn mathematics education. Tutak etal. (2011) stated that using culturally responsive teaching is to address cultural diversity like gender, ethnicity, experiences and capabilities of students while teaching mathematics in the classrooms. Culturally responsive education makes mathematics more meaningful by aligning instruction with the cultural paradigm and lived experiences of students (Beatty, 2016).

The girl participant stated as: "girls are seen poor in terms of enrollment, performance, participation and other activities in mathematics learning due to time factor, while I was at school, it was very difficult to select extra mathematics course for me because our teachers 
and parents discouraged me by saying that mathematics is difficult for girls, but I took it by struggling". This views indicate that she had faced gender stereotypes while learning and selecting mathematics course. Because she was unable to decide which course is important for her interest and at that time her teachers and parents discouraged her. But now she has her own self deciding level and thus such stereotypes have low influence. That is why time factor is one of the issue for gender construction in the society. These findings are supported by Gallagher and Kaufman (2015) who claimed that due to gender stereotype existed in the society always discourage girls to study mathematics and limits opportunities for women in mathematics and related fields. Furthermore, Ajai and Imoko (2015) the gender gap is mathematics achievements are due to classroom interactions; students' attitudes, interest and self-esteem; teachers' gendered attitudes, curricular materials; beliefs, social and cultural norms.

Moreover, the female participant teacher has a wonderful experience which was as: one of girl student of her class was rest at home due to give the birth of new baby. At that time the final interview of internal and external evaluation of this course was done. She was not able to participate such interview. Due to which she was failed and need to give exam for next year. This was happened because of girls. This view indicates that our assignments as indicated in the curriculum of mathematics education, particularly in the course of Math Ed. 539 is not flexible which is not constructed from the principle of equity. If it would be flexible, then the girls' student did not wait for the next year.

However, the overall discussions show that there is not gender bias found in objectives, contents, teaching methodology, textbooks and evaluation process of the curriculum in general. The selected teachers have also experienced same thing excepts some fixed assignments modality. That means that the nonflexible evaluation practices for assignments have made injustice for the girls' students in the curriculum of Math Ed. 539.

\section{Conclusion and Recommendations}

Incorporating indigenous knowledge in the curriculum of teacher preparation courses and making that curriculum gender friendly are the recent concerns in higher mathematics education. The findings of this study reflect that there is sufficient space of incorporate indigenous knowledge in the curriculum of the course Math Ed.539. The inclusion of several cultural issues of mathematics educations including ethno-mathematics, the cultural dimension of curriculum, strong social turn in mathematics education, issues of cultural diversity, ethnographic and auto-ethnographic research methodologies are some aspects of indigenous knowledge which were acknowledged in the curriculum of Math Ed.539. The provision of writing long essays, articles and seminars in the curriculum are the activities of students where students can do work in indigenous knowledge.

Similarly, there is no gender disparity in the curriculum of Math Ed. 539 and there are implementation of gender friendly/sensitive and cultural relevant pedagogy in the classroom practices are the evident of addressing gender issue in that curriculum. However, the not flexible exam system implemented in the curriculum shows the curriculum is not highly prepared from equity principles. Finally, the following recommendations are coined from the analysis of the curriculum. 
- The inclusion of IK should be ensure in the implementation of the courses

- Some cultural practices which reflect IK in context of Nepal can be included in the curriculum as much as possible.

- Include emerging issues of inclusion of IK, importance of IK and ways of addressing IK in the development of curriculum has been recommended

- Inclusion of indigenous people in the process of curriculum preparation and development has been recommended.

- Equal participation of women and men in the process of curriculum preparation and development has been recommendation

- Use gender responsive pedagogy and gender responsive language in curriculum, textbooks and in the implementation process.

- Include gender sensitive pedagogy, issues of gender, ways of addressing gender disparity, equity and equality principles for gender in the curriculum of teacher preparation course in mathematics education.

- The gender dimension including the technological and cultural dimension of mathematics education need to incorporate into the curriculum

- The recent pedagogical skills addressing issues of IK and gender might be reintroduced in the curriculum of teacher preparation courses in mathematics education

- The policy of a flexible exam system should be implemented to address the equity principles of gender in mathematics education.

Acknowledgement: I want to acknowledge NORHEAD QUINTICT Project (Central Department of Education, TU, Kirtipur) for the financial supports to produce this valuable document and equally giving acknowledgement to the participants of this research for providing their experiences.

\section{References}

Acharya B.R. (2017). Studies in mathematics education. Kathmandu : Dikshant Publication: Kathmandu.

Doll, W. E. (1993). A post-modern perspective on curriculum. New York: Teachers College Press.

Abah, J., Mashebe, P. \& Denuga, D.D (2015). Prospect of Integrating African Indigenous Knowledge Systems into the Teaching of Sciences in Africa. Retrieved from: .http:// pubs.sciepub.com/education/3/6/1/index.html

Ajai, J.T. \& Imoko, I.I. (2015). Gender differences in mathematics achievement and retention scores: A case of problem-based learning method. International Journal of Research in Education and Science (IJRES), 1(1), pp. 45- 50. Retrieved from: https://files.eric. ed.gov/fulltext/EJ1105194.pdf

Battiste, M. (2002). Indigenous Knowledge and Pedagogy in First Nations Education: A Literature Review with Recommendation. Retrieved from: https://www.afn.ca/uploads/ files/education/24._2002_oct_marie_battiste_indigenousknowledgeandpedagogy_lit_ review_for_min_working_group.pdf

Beatty, R. (2016). Exploring Indigenous Culturally Responsive Mathematics. Retrieved from: https:/thelearningexchange.ca/culturally-responsive-mathematics/ 
Cela, E. (2016). Evaluating basic education curriculum from a gender perspective: Addressing gender stereotype in elementary school textbooks. CBU International Conference Proceeding. Doi: 10.12955/cbup.v4.812. Retrieved from : https://www.researchgate. net/publication/309096459

Chahine,I.C.(2013). Mathematics Teachers'Explorations of Indigenous Mathematical Knowledge System.Retrieved from: http://ciaem-redumate.org/memorias-icemacyc/130-535-2DR-C.pdf

Chigeza, P. \& Whitehouse, H. (2014) Incorporating Indigenous Students' Cultural Knowledge More Productively in Mathematics and Science Classrooms: One Focus for Pre-Service Teacher Education Research and Practice. Leadership in Indigenous Research Special Issue, pp. 45-53.

Chikaire, J., Osuagwu, C.O., Ihenacho, R.A., Oguegbuchulam, M. N., Ejiogu-Okereke, N., and Obi, K.U. (2012). Indigenous knowledge system: The need for reform and the way forward. Global Advanced Research Journal of Agricultural Science, 1 (8), pp. 201 209.Retrieved from: https://www.researchgate.net/publication/334544436

Ernest, P., Greer, B. \&Shreeraman, B. (Ed). (2009). Critical issues in mathematics education. Charlottte, NC: Information age publishing.

Gallagher, A.M and Kaufman, J.C. (2005). Gender Differences in Mathematics What We Know and What We Need to Know. In A. M. Gallagher \& J.C. Kaufman (Eds.), Gender differences in mathematics. New York: Cambridge university Press.

Gates, P. (2001). Issues in mathematics teaching. London and NY: Routledge and Falmer.

Hall, J. (2012). Gender issues in mathematics: An Ontario Perspective. Journal of Teaching and Learning, 8 (1) pp. $59-72$ ).

Hersh, R. (Ed) (1997) What is mathematics really? NY: Oxford University Press.

Hersh, R. (Ed.) (2006). 18 unconventional essays on the nature of mathematics. NY: Springer.

Jojo, Z.M.M. (2015). The use of Indigenous Materials in the Teaching and Learning of Geometry. J.Communication, 6 (1), pp. 48-56.

Jones, S. (2016). Gender Issues in Mathematics Education in Tanzania. Retrieved from: https:// www.researchgate.net/publication/301627720_Gender_Issues_in_Mathematics_ Education_in_Tanzania

Kaino, M.L. (2013). Traditional Knowledge in Curricula Designs: Embracing Indigenous in Classroom Instruction. Stud Tribes Tribals, 11 (1), pp. 83-88. Retrived from: http:// www.krepublishers.com/02-Journals/T\%20\%26\%20T/T\%20\%26\%20T-11-0-000-13Web/T\%20\&\%20T-11-1-000-13-ABST-PDF/S-T\&T-11-1-083-13-281-Kaino-L-M/ST\&T-11-1-083-13-281-Kaino-L-M-Tt.pdf

Kaino, L. M. and Kasanda, C. (2015).Some indigenous strategies in mathematics teaching: Taking the artefacts into the classroom. J. Communication, 6(1): 67-74. Retrieved from: http:// krepublishers.com/02-Journals/JC/JC-06-0-000-15-Web/JC-06-1-000-15-Abst-PDF/ JC-06-1-067-15-160-Kaino-L-M/JC-06-1-067-15-160-Kaino-L-M-Tx\%5B8\%5D.pdf 
Langill, S. (1999). Indigenous Knowledge: A Resource Kit for Sustainable Development Researchers in Dryland Africa. Retrieved from: https://idl-bnc-idrc.dspacedirect.org/ bitstream/handle/10625/32058/114518.pdf?sequence=1\&isAllowed=y

Leder, G.C. (2019). Gender and Mathematics education: An overview. In G. Kaiser \& N. Presmeg (Eds.), Compendium for early career researchers in mathematics education, ICME-13,Monographs. Retrieved from: https://link.springer.com/ chapter/10.1007/978-3-030-15636-7_13

Leach, F. (2003). Practicing Gender Analysis in Education. UK: Oxfam GB.

Maaz, J. \&Schloeglmann, W. (Ed) (2006). New mathematics education research and practice. Rotterdam, The Netherlands: Sense

Ministry of Education (2015). Report on National Assessment of Students Achievement (NASA) 2013. Bhaktapur, Nepal: The Author. Retrieved from: https://ero.gov.np/upload_file/ files/post/1595313450_765892951_NASA_2013_Grade_8_Report.pdf

Moloi, T. (2013). The Teaching of Mathematics in Rural Learning Ecology Using Morabaraba Game (Board Game) as an Example of Indigenous Game. DoI: 10.7763/IPEDR, 60(26). Retrieved from: http://www.ipedr.com/vol60/026-ICEMI2013-K10022.pdf

Panthi, R.K and Belbase, S. (2017). Teaching and Learning Issues in Mathematics in the Context of Nepal. Retrieved from: https://files.eric.ed.gov/fulltext/ED573754.pdf

Senanayake, S.G.J.N.(2006). Indigenous knowledge as a key to sustainable development. The Journal of Agricultural Sciences, 2 (1), pp. 87 - 94. Retrieved from: https://www. researchgate.net/publication/265197993_Indigenous_knowledge_as_a_key_to_ sustainable_development.

Subedi, A. (2018). Bridging Indigenous Knowledge to Build Capacity in Teaching/Learning Mathematics. An unpublished action research submitted NORHEAD QUINTICT Project, Central Department of Education, Tribhuvan University, Nepal.

Thomas, D.R. (2006).A General Inductive Approach for Analyzing Qualitative Evaluation Data. American Journal of Evaluation, 27(2),pp. 237 -246. DOI: 10.1177/1098214005283748

Tsindoli, S., Ongeti, K. \&Chang'ach, J. K. (2018). Integration of existing indigenous knowledge within mathematics curriculum for Primary Schools in Kenya. International Academic Journal of Social Science and Education, 2 (1), pp. 74 - 87. Retrieved from: https:// www.iajournals.org/articles/iajsse_v2_i1_74_87.pdf

Tutak, F. A., Bondy, E. \& Adams, T.L (2011). Critical Pedagogy for critical mathematics education. International Journal of Mathematics Education in Science and Technology, Vol. 42 (1), 65-74. Available from: https://www.researchgate.net/publication/232819503_Critical_ pedagogy_for_critical_mathematics_education

Yacoubi, N. E. (2015). Gender and Mathematics Education in Africa. Retrieved from: https:// www.researchgate.net/publication/299822386_Gender_and_Mathematics_Education_ Revisited 